\title{
Effects of DME's Temperature on Power Performance of a Turbocharged DME Engine
}

\author{
Junhua $\mathrm{Wu}^{1, *}$, Zhen Huang ${ }^{2}$, and Wugao Zhang ${ }^{2}$ \\ ${ }^{I}$ Automobile and Traffic Engineering, Nanjing Forestry University, Nanjing 210037, China \\ ${ }^{2}$ Mechanical and Power Engineering, Shanghai Jiao Tong University, Shanghai 200240, China
}

\begin{abstract}
The present paper investigates into the effect of dimethyl ether (DME) temperature on a turbocharged DME engine that is used as a research object. The research results show that the DME temperature rises gradually in fuel tank during the engine running, and the system temperature is balanced after a period of time. When the DME temperature rises from $28^{\circ} \mathrm{C}$ to $40^{\circ} \mathrm{C}$, the engine power decreases by $8.0 \%$ from $132.2 \mathrm{~kW}$ to $121.6 \mathrm{~kW}$ in $1400 \mathrm{r} / \mathrm{min}$; it decreases by $12.0 \%$ from $192.1 \mathrm{~kW}$ to $168 \mathrm{~kW}$ in $2200 \mathrm{r} / \mathrm{min}$. At the rated working conditions, the DME engine power decreases by averagely $1.0 \%$ when the DME's temperature rises by $1^{\circ} \mathrm{C}$.
\end{abstract}

Keywords: DME temperature, turbocharged, DME engine, power performance, CLC number: TK464 literature code: A.

\section{INTRODUCTION}

Recently, DME has been highlighted increasingly as it can realize high-efficiency and low-pollution combustion and improve the energy structure in China thanks to its special properties. Foreign and Chinese researches have show that the DME can achieve highly efficiently and ultra-low emissions, mild combustion, zero smoke test value and low combustion noise [1-4]. In recent years, the technical center for combustion and environment in Shanghai Jiao Tong University has developed urban DME bus. Its power exceeds the level of the original diesel engine. The emission based on the mechanical pump reaches the national Level III emission standard. The noise decreases drastically by comparing to the diesel prototype engine [5-7]. Moreover, the center has been also committed to the development of DME engine industrialization application. During the experiment, it found that the DME engine power reduced by more $20 \mathrm{~kW}$ under the rated working condition than the initial cold start up state when the engine operates continuously for more than an hour. The instability of output power affects the massive promotion and application inevitably. The present paper intensively investigates into the temperature characteristics of DME supply system in DME engine and the effect of DME temperature on the engine performance.

\section{THE TEST EQUIPMENT AND METHODOL- OGY}

The DME engine under the experiment is developed by Shanghai Jiao Tong University based on the D6114ZLQB diesel engine manufactured by Shanghai Diesel Co., Ltd. D6114ZLQB engine is a turbocharged inter-cooled directly- injected diesel engine. The engine's main technical parameters are listed in Table 1. With modification of the engine, the DME engine is better than the original diesel in the power performance (see Fig. 1) [8].

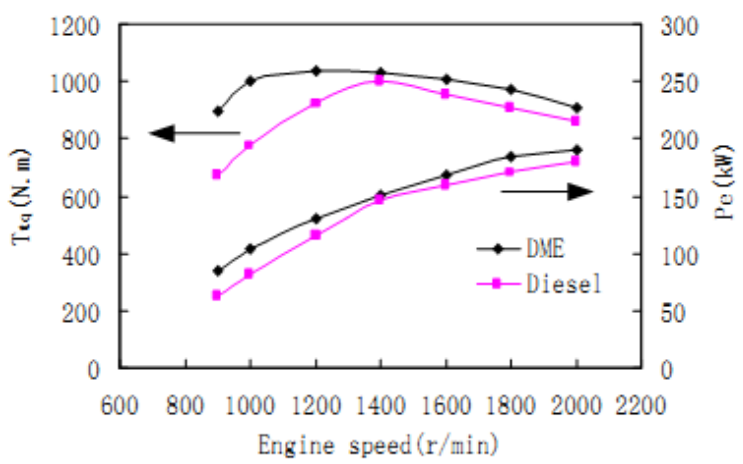

Fig. (1). Comparison of torque and power of DME engine and diesel engine at full load.

To reveal the effect law of DME temperature on DME engine power, the present paper investigates the temperature variation rule of DME supply system at steady engine running state. $50 \mathrm{~kg}$ MDE is stored in the tank. The MDE engine runs respectively at both $132.2 \mathrm{~kW}$ in $1400 \mathrm{r} / \mathrm{min}$ and $192.1 \mathrm{~kW}$ in $2200 \mathrm{r} / \mathrm{min}$. During the experiment, the throttle position is kept unchanged. The temperature of each test point in the DME supply system is tested. The test points include DME tank outlet, high pressure oil pump inlet and outlet. The output power of engine is measured at each temperature test point.

\section{TEST RESULTS AND ANALYSIS}

Fig. (2) shows the variation of temperature with time in DME system. The initial temperature at DME tank outlet is 
Table 1. The Specifications of Diesel Engine and DME engine.

\begin{tabular}{|c|c|c|}
\hline & Diesel Engine & DME Engine \\
\hline \hline Model & D6114ZLQB & $114 \times 135 \mathrm{~mm} \times \mathrm{mm}$ \\
\hline Cylinder diameter x range & $114 \times 135 \mathrm{~mm} \times \mathrm{mm}$ & $8.27 \mathrm{~L}$ \\
\hline Displacement & $8.27 \mathrm{~L}$ & $18: 1$ \\
\hline Compression ratio & $18: 1$ & $9 /\left({ }^{\circ} \mathrm{CA}\right.$ BTDC) \\
\hline Injection advance angle & $9 /\left({ }^{\circ} \mathrm{CA} \mathrm{BTDC}\right)$ & $1000 \mathrm{~N} . \mathrm{m} / 1400 \mathrm{r} / \mathrm{min}$ \\
\hline Max. torque/rpm & $1000 \mathrm{~N} \cdot \mathrm{m} / 1400 \mathrm{r} / \mathrm{min}$ & $\mathrm{P} 8500$ \\
\hline Injection pump & $\mathrm{P} 7100$ & $13 \mathrm{~mm}$ \\
\hline Piston diameter & $12 \mathrm{~mm}$ & $6 \times 0.4 \mathrm{~mm}$ \\
\hline Nozzle number x nozzle diameter & $6 \times 0.24 \mathrm{~mm}$ & \\
\hline
\end{tabular}

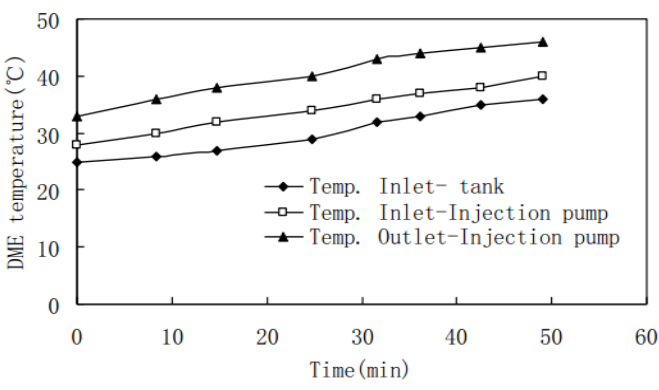

(a) $1400 \mathrm{r} / \mathrm{min}$

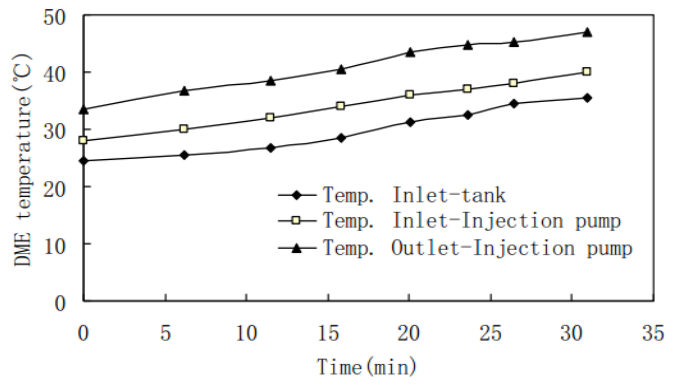

(b) $2200 \mathrm{r} / \mathrm{min}$

Fig. (2). Variation of DME temperature with time (injection advance angle $8^{\circ} \mathrm{CA}$ BTDC, P8500 Pump, $12 \mathrm{~mm}$ Piston, $6 \times 0.43 \mathrm{~mm}$ Nozzle).

$25^{\circ} \mathrm{C}$, and the temperature at the high pressure oil pump inlet is $28^{\circ} \mathrm{C}$. The DME temperature rises after passing through the high pressure oil pump. The initial temperature at high pressure oil pump outlet is $32^{\circ} \mathrm{C}$. In the working condition of $132.2 \mathrm{~kW}$ in $1400 \mathrm{r} / \mathrm{min}$, the temperature of DME supply system in DME engine is basically balanced. The temperature at the DME tank outlet is $37^{\circ} \mathrm{C}$, the temperature at the high pressure oil pump inlet is $40^{\circ} \mathrm{C}$ and the temperature at the high pressure pump outlet is $46^{\circ} \mathrm{C}$. In the working condition of $192.1 \mathrm{~kW}$ in $2200 \mathrm{r} / \mathrm{min}$, the initial temperature in the DME tank outlet is $24.6^{\circ} \mathrm{C}$, the temperature at the high pressure oil pump inlet is $28^{\circ} \mathrm{C}$ and the temperature at the high pressure pump outlet is $33.6^{\circ} \mathrm{C}$. The DME supply system reaches a balance state in a shorter time by $30 \mathrm{~min}$ as the engine consumes more DME and the high pressure oil pump produces more heat at running. The temperature at the DME tank outlet is $37^{\circ} \mathrm{C}$, the temperature at the high pressure oil pump inlet is $40^{\circ} \mathrm{C}$ and the temperature at the high pressure oil pump is $46.9^{\circ} \mathrm{C}$.

Fig. (3) shows the effect of DME temperature on DME engine power. It can be known from Fig. (3) that the engine power is reduced from $132.2 \mathrm{~kW}$ to $121.6 \mathrm{~kW}$, downturned by $8 \%$ in $1400 \mathrm{r} / \mathrm{min}$; the engine power is reduced from $192.1 \mathrm{~kW}$ to $168 \mathrm{~kW}$, downturned by $12.0 \%$, in $220 \mathrm{r} / \mathrm{min}$ when the DME temperature at the high-pressure pump inlet rises from $28^{\circ} \mathrm{C}$ to $40^{\circ} \mathrm{C}$. In the rated working condition, the DME engine power averagely reduces by $1.0 \%$ when the DME temperature rises by $1^{\circ} \mathrm{C}$.

The elevated DME temperature causes a higher engine power. We can expound in following aspects:

(1) The rising temperature causes the decrease of temperature. In the same throttle position, the actual DME injection amount reduces and leads to the decrease of DME engine power

When the liquid-phase DME temperature rises, the DME volume and the density will change. AT atmospheric pressure, DME volume variation with temperature is shown in Tables 2 to 4 [9]. The DME density variation with the temperature can be reckoned as per the data given in Table 2 (Fig. 3). At liquid-phase DME temperature $28^{\circ} \mathrm{C}$, its density is $0.645 \mathrm{~g} / \mathrm{ml}$. When the liquid-phase DME temperature is 


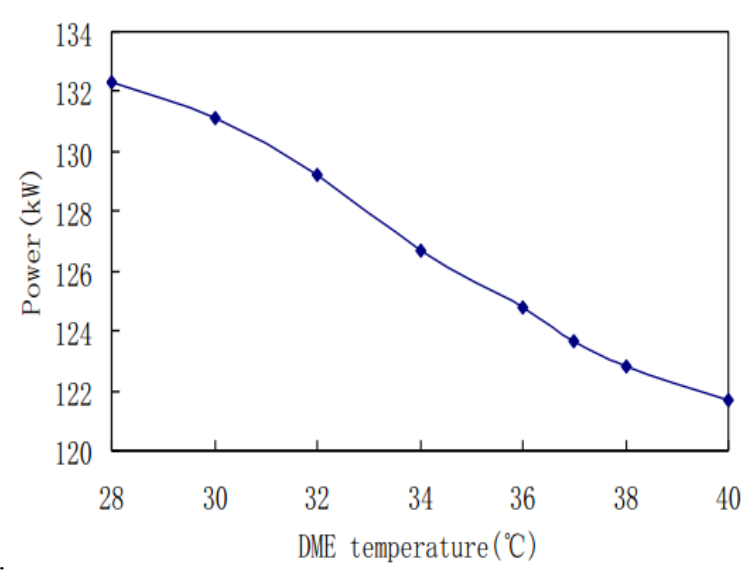

(a) $1400 \mathrm{r} / \mathrm{min}$

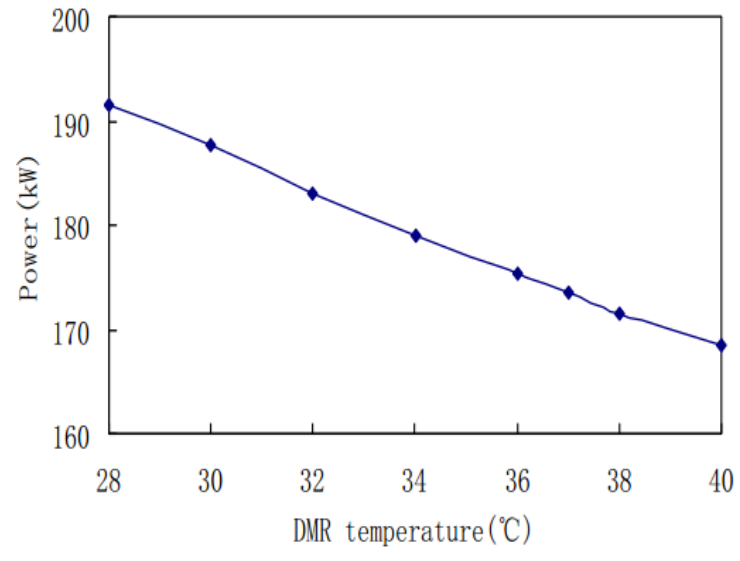

(b) $2200 \mathrm{r} / \mathrm{min}$

Fig. (3). Effect of DME temperature on power of DME engine (injection advance angle $8^{\circ} \mathrm{CA}$ BTDC, P8500 Pump, $12 \mathrm{~mm}$ piston, $6 \times 0.43$ $\mathrm{mm}$ nozzle).

$40^{\circ} \mathrm{C}$, its density is $0.628 \mathrm{~g} / \mathrm{ml}$; the DME temperature rises from $28^{\circ} \mathrm{C}$ to $40^{\circ} \mathrm{C}$, its density decreased by $2.6 \%$.

The rising temperature leads to the increase of saturated DME vapor pressure. The increased vapor pressure is easier to cause the air resistance, the large tendency of generating cavitation when the delivery valve at oil pump is seated, and the decrease of engine power.

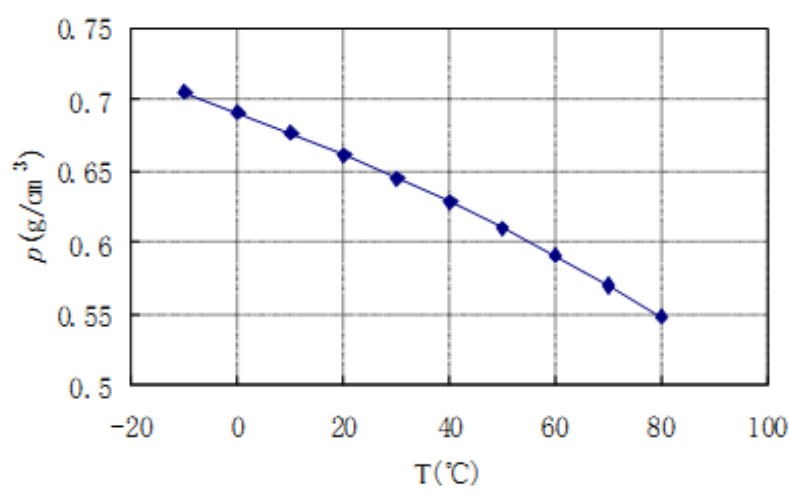

Fig. (4). Effect of temperature on Density of DME.

Fig. (5) shows the effect of temperature on the saturated vapor pressure. When the liquid-phase DME temperature is $20^{\circ} \mathrm{C}$, its saturated vapor pressure is $0.51 \mathrm{MPa}$; when the liquid-phase $\mathrm{DME}$ temperature is $50^{\circ} \mathrm{C}$, the saturated vapor pressure is $1.16 \mathrm{MPa}$, and the DME supply system pressure in DME engine is 1.2 MPa. After the DME temperature rises, the saturated vapor pressure is close to the oil supply system pressure, the system's air resistance is serious and the engine power is resultantly reduced.

When the rising temperature causes the decrease of DME elastic modulus, the DME is easily compressed. The decreased DME acoustic speed in high-pressure oil tubing and less actual DME amount into the nozzle at the same throttle positions lead the decrease of DME engine power as well.

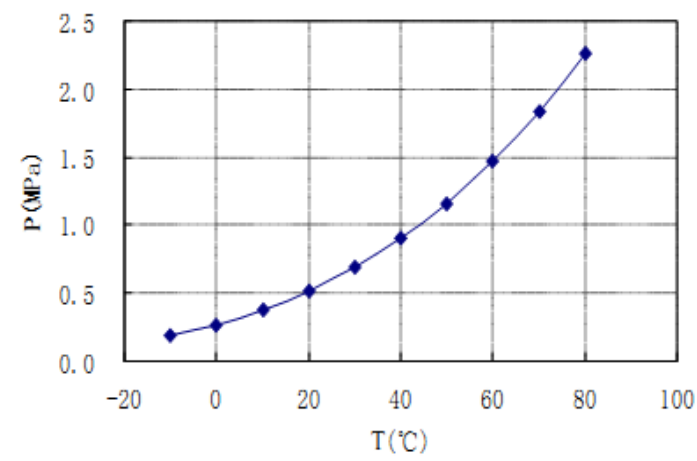

Fig. (5). Effect of temperature on vapor pressure of DM.

Table 2. Volume change of DME with temperature.

\begin{tabular}{|c|c|c|c|c|c|c|c|c|}
\hline $\mathbf{T} /$ & -10 & 0 & 10 & 20 & 30 & 40 & 50 & 60 \\
\hline $\begin{array}{l}\mathrm{V} /(\mathrm{cm} \\
3 / \mathrm{mol})\end{array}$ & 5.235 & 66.583 & 68.049 & 69.633 & 71.358 & 73.238 & 75.424 & 77.845 \\
\hline
\end{tabular}

\section{CONCLUSION}

(1). DME temperature has a significant effect on the engine power performance. At the rated working points, the DME engine power declines averagely by $1.0 \%$ when the DME temperature rises by $1^{\circ} \mathrm{C}$.

(2). To ensure the stability of DME engine power, the DME temperature must be controlled in application. The special constant-temperature system can be used for temperature control. The DME temperature range should be specified in the nominal power of the DME engine.

\section{CONFLICT OF INTEREST}

The author confirms that this article content has no conflict of interest. 


\section{ACKNOWLEDGEMENTS}

This work was supported by National Natural Science Foundation of China (51176119).

\section{REFERENCES}

[1] T. Fieisch, C. M. Carthy, and A. Basu, "A new clean diesel technology: demonstration of ULEV emissions on an avistar diesel engine fueled with dimethyl ether", in SAE Paper 950061. Warrendale, USA: Society of Automotive Engineers, Inc, 1995.

[2] M. Y. Kin, S. H. Yoon, and B. W. Ryu, "Combustion and emission characteristics of DME as an alternative fuel for compression ignition engines with a high pressure injection system", Fuel, vol. 87, no. 12 , pp. 2779-2786, 2008.

[3] L. Chen, "Engine performance and exhaust gas characteristics of a compression ignition engine operated with DME blended gas oil fuel”, in SAE Paper 982538, 1998.
[4] M. Oguma, S. Goto, "Research and development of a medium duty DME truck", in NSFC/JSPS Workshopin AIST, Tsukuba, Japan, March 2006.

[5] J. J. Zhang, X. Q. Qiao, and B. Guan, "Experiment on CCCI combustion in an engine fueled with DME", Transactions of the Chines Society for Agricultural Machinery, vol. 39, no. 6, pp. 13-16, 2008.

[6] J. J. Zhang, X. Q. Qiao, and B. Guan, "An experimental investigation of optimizing control of compound charge compression ignition (CCCI) combustion in an engine fueled with DME", Transactions of CSICE, vol.26, no.3, 2008.

[7] J. H. Wu, Z. Huang, and X. Q. Qiao, "Study on combustion and emissions characteristics of turbocharged engine fuelled with dimethyl ether", Int J Automotive Technology, vol. 7, no. 6, pp. 645-652, 2006.

[8] J. H. Wu, "Experimental investigation of combustion and emissions on a turbocharged DME engine". Shanghai: Shanghai Jiao Tong University, 2007.

[9] Y. B. Liang, and J. S. Tong, "Study on the thermodynamic properties of liquid fuel substitute-dimethyl ether", Chemical Engineering (China), vol. 31, no. 1, pp. 60-62, 2003

(C) Yu et al.; Licensee Bentham Open.

This is an open access article licensed under the terms of the Creative Commons Attribution Non-Commercial License (http://creativecommons.org/licenses/by-nc/3.0/) which permits unrestricted, non-commercial use, distribution and reproduction in any medium, provided the work is properly cited. 